\title{
Programa Mais Médicos sob o olhar dos usuários: uma pesquisa avaliativa
}

\author{
I ${ }^{1}$ Priscila Meira Mascarenhas Padre, ${ }^{2}$ Ismar Eduardo Martins Filho, \\ ${ }^{3}$ Vanda Palmarella Rodrigues I
}

Resumo: O Programa Mais Médicos (PMM) surge em 2013 como medida para enfrentar a ausência de médico na atenção básica. Gerou polêmicas na sociedade diante da abertura do mercado brasileiro para profissionais estrangeiros, com desaprovação por parte da categoria médica, mas com aparente aceitação popular. Assim, este estudo objetivou avaliar a implantação do PMM de um município no interior baiano por meio dos usuários. Tratase de uma pesquisa avaliativa realizada em 11 equipes de saúde da família em um município no interior da Bahia, que possuíam médicos vinculados pelo Programa, tendo a participaçáo de 30 usuários. Realizou-se entrevista semiestruturada e os dados foram analisados de acordo com a técnica de análise de conteúdo temática. Foi também construída uma matriz de julgamento de modo a apontar o mérito alcançado pelo PMM. Os resultados revelaram que a implantação do Programa foi satisfatória, havendo forte aprovação popular em torno dele, mesmo existindo um conhecimento superficial acerca do mesmo, ou até um desconhecimento total. Foi evidenciado ainda que não seria necessária a vinda de médicos estrangeiros para o país, uma vez que fossem realizados os devidos ajustes na base jurídico-operacional do Programa de modo a atrair e fixar os profissionais brasileiros.

> Palavras-chave: direito à saúde; políticas públicas; atenção primária à saúde.

\author{
' Departamento de Saúde. \\ Universidade Estadual do Sudoeste \\ da Bahia. Jequié-BA, Brasil (priscila. \\ meira@yahoo.com.br). \\ ORCID: 0000-0001-9543-2233 \\ ${ }^{2}$ Departamento de Saúde. \\ Universidade Estadual do \\ Sudoeste da Bahia. Jequié-BA, \\ Brasil (iemfilho@uesb.edu.br). \\ ORCID: 0000-0002-1013-6951 \\ ${ }^{3}$ Departamento de Saúde. \\ Universidade Estadual do \\ Sudoeste da Bahia. Jequié-BA, \\ Brasil (vprodrigues@uesb.edu.br) \\ ORCID: 0000-0002-5689-5910
}

Recebido em: 22/03/2018 Revisado em: 02/03/2019 Aprovado em: 12/03/2019 


\section{Introdução}

Criado em julho de 2013 pelo governo federal, o Programa Mais Médicos (PMM) surgiu com a proposta de resolver os problemas relacionados à assistência médica na Atenção Primária à Saúde (APS), com a perspectiva de enfrentar a enorme disparidade da relação de médicos por mil habitantes entre os estados do país, além da questão distributiva e a escassez na oferta de médicos. Dessa forma, foram adotadas açóes de curto prazo com o provimento emergencial de médicos para as áreas mais vulneráveis, e de médio e longo prazos com a expansão das faculdades de medicina no país e ampliação do número de vagas nos cursos de residência, além de investimentos em infraestrutura das unidades de saúde (CARRYL; ROSSATO; PRADOS, 2016).

Estudo mostrou que um dos graves problemas da saúde no Brasil apresentados pela gestáo do Sistema Único de Saúde (SUS) e pela sociedade estava relacionado ao déficit de cobertura médica, a desigual distribuição desses profissionais no território nacional, com alta concentração nas capitais e regióes metropolitanas, em especial nas regiōes Sudeste e Sul, e com perfil de busca pela especialização profissional, indicando escassez de médicos com atuação voltada para a APS (CERQUEIRA; ALVES, 2016).

Desse modo, o PMM se apresentou como uma política pública formulada no intuito de privilegiar o atendimento aos cidadãos menos favorecidos, em que os médicos participantes do Programa são incumbidos de desenvolver suas atividades em lugares remotos, considerados de difícil acesso, bem como em municípios populosos com baixa renda per capita (BRASIL, 2013a). Nessa perspectiva, este Programa representou um avanço significativo na pauta de assuntos que compóem a agenda política do SUS na tentativa de solucionar a insuficiência de profissionais médicos na rede básica em âmbito nacional.

O PMM teve como finalidades a redução da carência de médicos nas regiōes prioritárias para o SUS; o fortalecimento da prestação de serviços na APS; o aprimoramento da formação médica no país, além de proporcionar maior experiência no campo de prática médica durante o processo de formação; a ampliação da inserção do médico em formação nas unidades de atendimento do SUS; o fortalecimento da política de educação permanente com a integração ensino-serviço; a promoção da troca de conhecimentos e experiências entre profissionais de saúde brasileiros e médicos 
formados em instituiçôes estrangeiras; o aperfeiçoamento médico nas políticas públicas de saúde do país e na organização e funcionamento do SUS; e o estímulo à realização de pesquisas aplicadas no SUS (PADILHA; OLIVA; BELCHIOR, 2013).

Para a fixação dos médicos nas regióes vulneráveis, o PMM estabeleceu critérios essenciais com a seguinte ordem de prioridade de acesso à participação: ao profissional formado em instituição de educação superior brasileira ou com diploma revalidado no Brasil, devendo possuir inscrição no órgão de classe; em seguida, o acesso do médico brasileiro, com formação em instituição de educação superior estrangeira e habilitação para exercício da medicina na forma da lei do respectivo país; e, por fim, em caráter residual de acesso, o estrangeiro formado em instituição estrangeira, com habilitação para exercício da medicina na forma da lei do respectivo país (BRASIL, 2013b).

Assim, as vagas oferecidas pelo Ministério da Saúde para atuação na atenção básica que não foram preenchidas por médicos brasileiros foram disponibilizadas para os médicos estrangeiros devidamente inscritos no Programa. Os editais que regulavam o PMM foram abertos a médicos estrangeiros que atuavam em países com proporção de profissionais por mil habitantes maiores que a do Brasil, ou seja, maior que 1,8. O governo federal priorizou países como Espanha, Portugal e Cuba, considerando a formação qualificada na APS e similaridade da língua (BRASIL, 2014).

No entanto, desde o anúncio do PMM, vários foram os debates envolvendo diferentes sujeitos sociais e matizes ideológicas, com confronto mais acirrado entre os representantes do governo e sua base de sustentação no Congresso Nacional e as corporaçôes médicas, sobretudo o Conselho Federal de Medicina (CFM). Assim, o Programa repercutiu nas entidades médicas, no governo, na mídia e sociedade, gerando muitos embates (MORAIS et al., 2014).

Um desses enfrentamentos decorreu do questionamento de que o termo de cooperação técnica firmado pelo Brasil e a Organização Pan-Americana de Saúde (OPAS) para intercambiar profissionais não podia ser considerado um convênio, pois dispensava determinados mecanismos de controle, principalmente chamamento público para eleição da melhor proposta ao programa de governo, e a desvinculação do poder público perante as obrigaçôes cíveis e trabalhistas da entidade convenente. Além disso, a aquisição de produtos e a contratação de serviços com recursos da União transferidos a entidades privadas sem fins lucrativos, sem observar os 
princípios da impessoalidade, moralidade e economicidade, sendo necessária, no mínimo, a realização de cotação prévia de preços no mercado antes da celebração do contrato (DI JORGE, 2013).

Outros aspectos foram trazidos por Cerqueira e Alves (2016), ao referirem que o cumprimento de princípios constitucionais do SUS da universalidade, isonomia na cobertura médica e ordenação de recursos humanos em saúde não podiam suplantar a violação aos princípios igualmente constitucionais dos direitos sociais do trabalho e do concurso público. Assim sendo, não se podia acentuar o grau de um princípio constitucional em detrimento de outro, conforme valores essenciais à sociedade em dado tempo e conjuntura.

Desse modo, de um lado, a referida política pública propiciava melhoria da assistência prestada à população, uma vez que solucionava um problema histórico vivenciado no cotidiano dos serviços, que é a carência do médico nas áreas mais remotas do país; mas por outro lado, não estava juridicamente respaldada, segundo enfatizavam alguns setores da sociedade, posto que a forma de ingresso ocorria sem a devida concorrência tal como preconizado pela lei e a forma de contratação apresentava caráter ilegal, pois não contemplava o vínculo empregatício.

Pesquisa avaliativa realizada com usuários sobre o PMM mostrou que o Programa se configurou um avanço para o SUS porque colaborou para a ampliação do acesso ao médico em regiōes mais vulneráveis do Brasil, alinhandose aos esforços internacionais de provimento de pessoal para a saúde. Apontaram como aspectos positivos do PMM, a ampliação do acesso aos cuidados médicos, apesar das barreiras organizacionais e técnicas que limitavam o uso dos serviços. Enfatizaram ainda a relação médico-usuário humanizada, caracterizada pela escuta, atenção e diálogo, apesar de o idioma ter se configurado como uma barreira encontrada (SILVA et al., 2016).

Diante do exposto, o estudo do referido tema é de extrema relevância, pois contribuiu para avaliar o PMM sob o ponto de vista dos usuários assistidos no cotidiano dos serviços de saúde na APS, com a perspectiva de uma aproximação da realidade vivenciada por estes, de modo a adequá-lo mediante suas opiniôes. Tendo como objetivo conhecer a opiniáo dos usuários sobre o PMM e avaliar a implantação do PMM de um município no interior baiano por meio dos usuários. 


\section{Percurso metodológico}

Trata-se de uma pesquisa avaliativa, com desenho de avaliação dos efeitos, resultado de uma dissertação de mestrado. Foi realizada em 11 equipes de Saúde da Família (eSF), distribuídas em nove unidades de saúde, em um município no interior da Bahia. É classificada como pesquisa de avaliaçáo por ter se dedicado a analisar uma política pública, sendo entendida como a tentativa de se estabelecer uma relação de causalidade entre um programa e um resultado, visando compará-lo a um padrão ou aquilo que é tido como ideal/referência (CRUZ, 2015).

$\mathrm{O}$ processo de seleção se deu por aquelas equipes que possuíam médicos vinculados através do PMM. A coleta de dados ocorreu entre maio e junho de 2017, contando com a participação de 30 usuários adscritos nas referidas eSF, selecionados segundo critérios de inclusão: ter idade maior ou igual a 18 anos e estarem presentes na unidade de saúde aguardando atendimento no momento da visita do pesquisador.

Realizou-se entrevista semiestruturada na sala de espera com os usuários que aceitavam participar da pesquisa em dias alternados, orientada por um roteiro previamente elaborado, que foi submetido a teste piloto em uma eSF de um município vizinho. A entrevista teve o apoio de um gravador, sendo precedida da assinatura no Termo de Consentimento Livre e Esclarecido pelos participantes. O projeto de pesquisa foi encaminhado para análise e aprovado pelo Comitê de Ética em Pesquisa da Universidade Estadual do Sudoeste da Bahia, sob CAAE 58813016.4.0000.0055 e protocolo no $1.770 .394 / 2016$.

Os informantes foram identificados no texto pela letra "E" de Entrevistado, acompanhada do número da entrevista, como exemplo: E1, E2, E3. Os dados foram analisados de acordo com a técnica de análise de conteúdo temática.

As etapas desta técnica foram organizadas em três fases. A primeira fase, pré-análise, foi desenvolvida para sistematizar as ideias iniciais. A exploração do material, segunda fase, consistiu na construção das operaçôes de codificação, considerando-se os recortes dos textos em unidades de registros. E a terceira fase compreendeu o tratamento dos resultados, inferência e interpretação, consistindo em captar os conteúdos manifestos e latentes contidos em todo o material coletado (BARDIN, 2011).

Assim, emergiram da técnica de análise de conteúdo as seguintes categorias e subcategorias: entendimento sobre o PMM (desconhecimento, aumento na 
quantidade de profissionais médicos e médicos provenientes de outros países); opiniáo acerca do PMM (facilita o acesso à consulta médica, aumento da oferta de médicos no Brasil, estabelecimento de vínculo entre profissional e usuário, priorizar a contratação de médicos brasileiros, aumento de custos para o Brasil e não aprovação); e atendimento do profissional médico (atende bem, facilidade na comunicação, dificuldade na comunicação e preferência pelo profissional anterior).

Foi também construída uma matriz de julgamento, utilizada no campo da avaliação em saúde como forma de expressar a lógica causal de uma intervenção, traduzindo como seus componentes contribuem na produção dos efeitos, favorecendo sínteses em forma de juízos de valor (ALVES et al., 2010). Esta matriz foi adaptada a partir da elaborada por Figueiró e Cazarin (2010) para o Programa de Controle Nacional da Dengue, sendo elencados os critérios/indicadores de processo a partir das falas emanadas das entrevistas realizadas.

Cada dimensão desta recebeu uma classificação (exemplo: satisfatório, insatisfatório, adequado, inadequado) a partir da avaliação referida pelos usuários. Para cada classificação foi atribuído um valor, que após a soma de todas as dimensões de análise gerou uma pontuação final que definiu o julgamento do programa a partir do ponto de vista dos entrevistados. Assim, o procedimento possibilitou a classificação do grau de implantação do PMM, sendo incipiente se o valor final alcançado fosse $\leq 33,3 \%$; parcial ou média se estivesse entre $33,3 \%$ e $66,6 \%$; e satisfatória ou plena, se fosse maior que 66,6\% (ALVES et al., 2010).

\section{Resultados e Discussão}

Após o estudo das falas, surgiram sete critérios que foram analisados na matriz (Quadro 1): atendimento resolutivo, oferta dos serviços organizada, garantia de acesso ao serviço de saúde, melhoria do atendimento após a implantação do programa, conhecimento dos usuários acerca do PMM, aprovação do PMM pelos usuários e equipe de saúde completa, que geraram uma avaliação de acordo com os parâmetros estabelecidos na matriz e produziram um julgamento final de que a implantação do PMM no município em estudo foi satisfatória ou plena. 


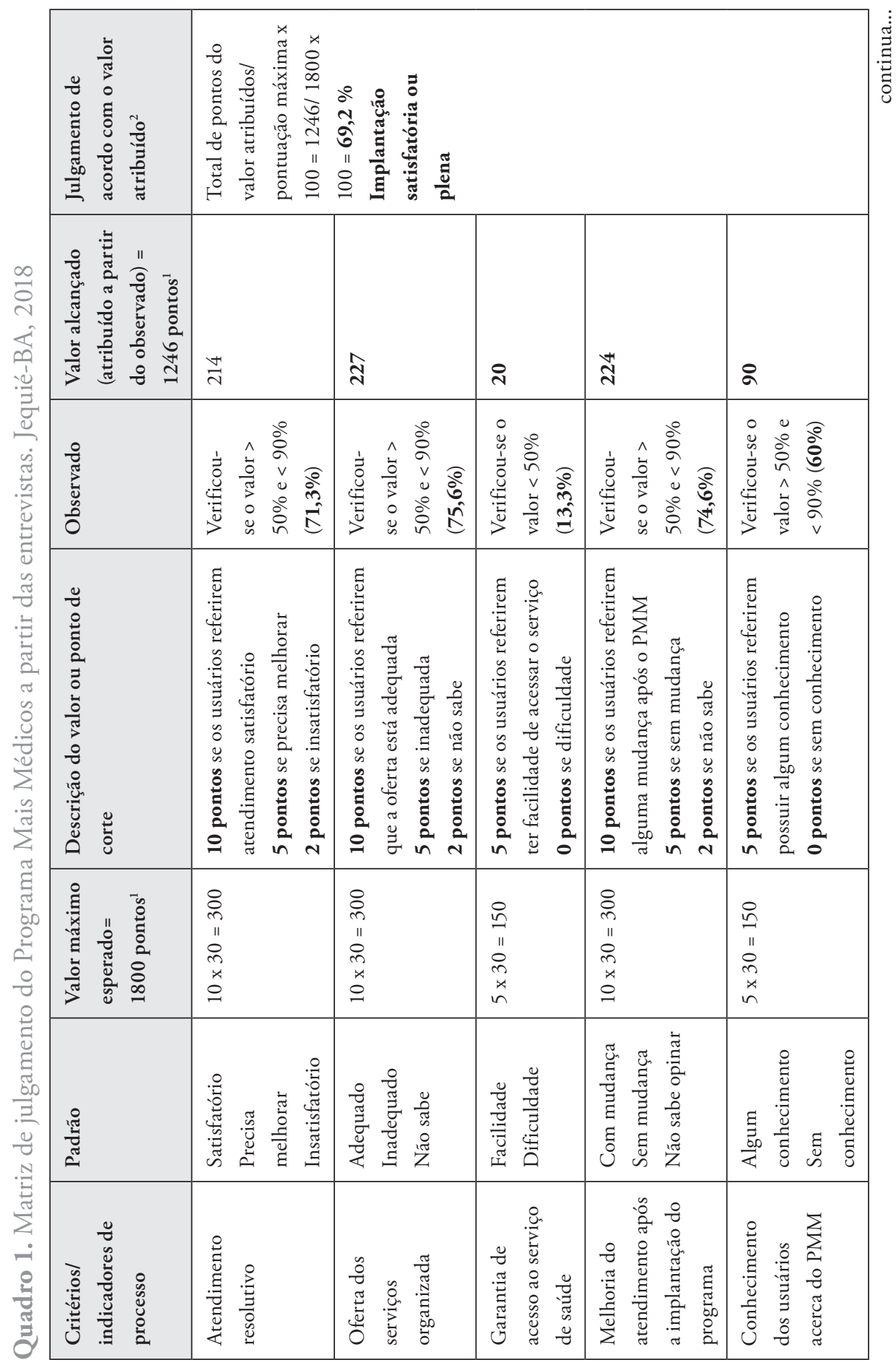


| Página 8 de 23

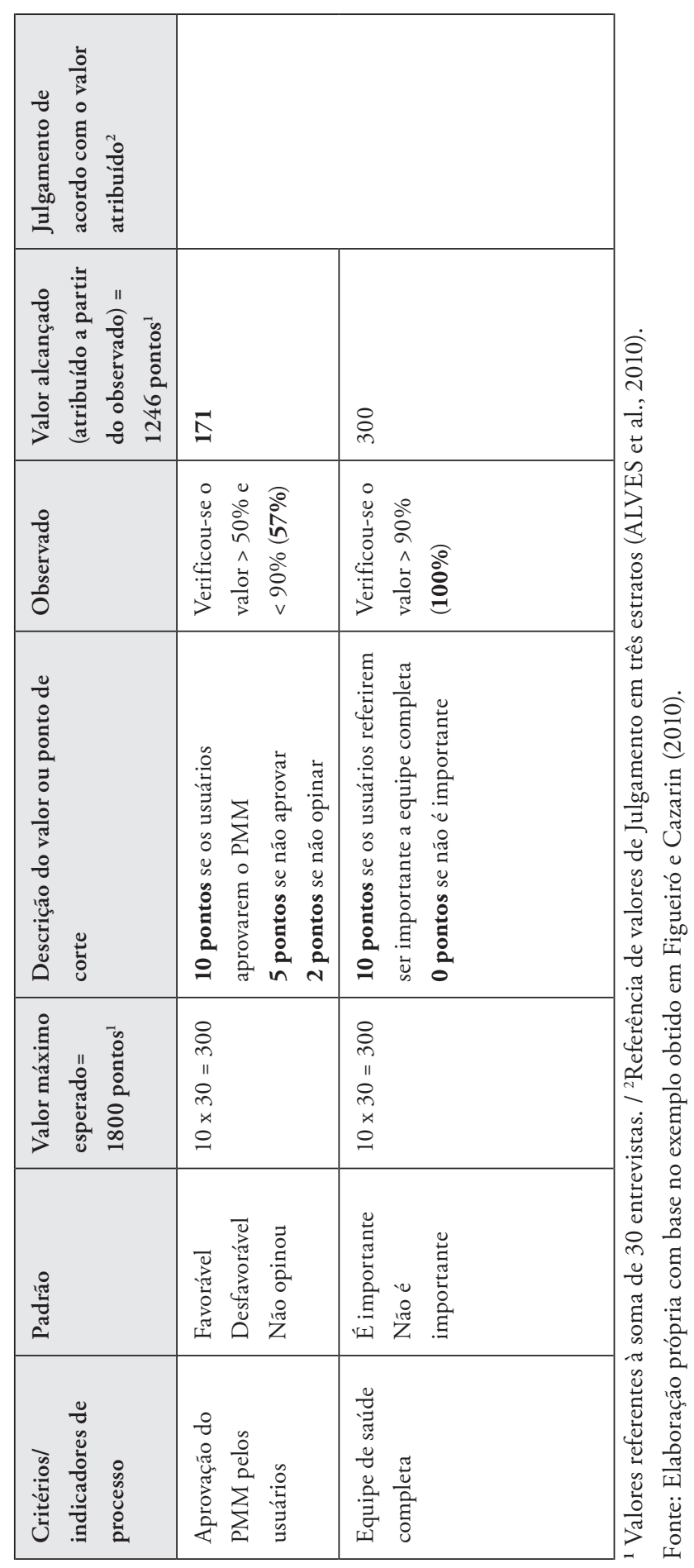


A análise dos dados mostrou que, apesar da implantação ter sido classificada como satisfatória ou plena, ainda existia desconhecimento por parte da comunidade acerca do PMM, visto que apenas 60\% dos entrevistados referiram ter algum conhecimento sobre o mesmo, conhecimento este incipiente na maioria das falas, em decorrência da pouca divulgaçáo junto à comunidade.

As entrevistas evidenciaram o entendimento dos usuários sobre o PMM, com destaque para o desconhecimento do referido programa, conforme relatos a seguir.

Não, nunca ouvi falar (E1).

Não, já ouvi falar, mas não prestei atenção não (E14).

Tal fato revelou que os usuários, apesar de sentirem melhorias na assistência recebida, não detinham informação a respeito do Programa nem possuíam conhecimento sobre o mesmo, e aqueles que conheciam, eram de forma incipiente.

Os usuários destacaram ainda que o PMM propiciou o aumento da quantidade de profissionais médicos.

Já, que vai ter mais médico pras pessoas (E3).

Já ouvi, só ouço falar do programa mais médico pra trazer mais médico pra cidade, pros postos, essas coisas (E5).

Diante do exposto, evidenciou-se a necessidade de maior divulgação do PMM, já que a comunicação em saúde possui uma abordagem multifacetada e multidisciplinar para alcançar diferentes públicos e compartilhar informaçôes com o objetivo de influenciar, engajar e prover suporte a indivíduos, comunidades, profissionais de saúde, gestores, políticos, para defender, introduzir, adotar ou sustentar um comportamento, prática ou política, culminando na melhoria dos resultados de saúde (SCHIAVO, 2007).

Os usuários entendiam ainda que o PMM estava associado à ideia de médicos provenientes de outros países.

Sei, que vem os médicos de fora atender (E4).

Já, já ouvi falar desses médicos que vieram de fora pra aqui pro Brasil (E13).

Já, que os médicos que tava vindo de fora que tava em falta de médico, pra melhorar o atendimento (E25).

Uma pesquisa realizada na Paraíba corroborou os achados do presente estudo, posto que demonstrou que os usuários tinham total desconhecimento sobre a origem, 
a formulação e os objetivos do PMM, e que, apesar de o beneficiário focar o interesse em ser bem atendido, sua desinformação fragilizava o controle social no contexto das políticas públicas, na medida em que impossibilitava a cobrança das responsabilidades e dos papéis previamente definidos (SOUSA; OLIVEIRA SILVA, 2015).

Desse modo, o fato de a comunicação ocorrer muitas vezes de forma preordenada e com pautas decisionais já estabelecidas, com baixíssimos níveis de reflexividade perante os membros da comunidade atingidos pelas decisóes tomadas e executadas, pode estar relacionado à falta de controle social do exercício do poder político. Não se devendo usar o argumento de que a complexidade da administração pública dificulta a participação social, uma vez que tal retórica inviabiliza a compreensão de suas práticas, sendo-lhe vedado o alcance dos níveis de discussão e deliberação sobre a concepção daquelas ações e políticas (LEAL, 2013).

Nesse contexto, os veículos de comunicação de massa, como o jornal impresso, televisão, internet, dentre outros, consistem em importantes meios de divulgação de informaçôes de saúde para parcelas significativas da população (MORAIS et al., 2014). Desse modo, ficou evidente que uma maior divulgação acerca do PMM poderia contribuir para seu fortalecimento, uma vez que o empoderamento do sujeito foco das ações permitiria a realização de debates, esclarecimento de dúvidas, aperfeiçoamento de falhas e efetivação do mesmo como uma política de Estado e não de governo.

A partir da matriz de avaliação (quadro 1), observou-se ainda que 100\% dos usuários consideravam importante a equipe de saúde estar completa; e que somente 13,3\% dos mesmos encontravam facilidade para acessar o serviço de saúde, relatando dificuldades relacionadas à falta de cirurgião-dentista, de medicamentos e de exames complementares, não sendo a ausência do médico um problema por eles referido, o que mostrou que somente a presença deste profissional não solucionava todos os problemas da atenção básica. Tendo sido verificado também que, apesar disso, a oferta dos serviços oferecidos estava bem organizada, o que foi referido por $75,6 \%$ dos participantes da pesquisa.

Sobre esta questão, a análise das entrevistas ora trabalhada ratificou o que foi verificado na matriz, ao evidenciar a opiniâo dos usuários sobre o PMM.

Observou-se uma opiniáo positiva acerca do Programa com ênfase na facilidade de acesso à consulta médica. 


\begin{abstract}
Quanto mais médico, melhor pra atender a população, a população não fica tão carente, no posto não fica lotação e nem vai pros pronto socorro que é carente também, fazendo aglomeração, e acaba sendo prejudicial, se prejudica mais do que estava antes (E7).

Eu achei bom, porque é mais médico e a gente tem mais atendimento, não é só um só pra área toda, igual agora tem dois médicos pra uma área e pra outra (E10).

Antes não conseguia marcar, tinha a dificuldade de conseguir médico, e agora melhorou bastante (E13).
\end{abstract}

Estas falas retratam que os entrevistados se mostraram satisfeitos ao encontrar o atendimento no momento em que necessitavam e que compreendiam que a porta de entrada preferencial para resolução de seus problemas de saúde é a unidade básica de saúde, pois não precisavam se deslocar até os serviços de urgência-emergência, muitas vezes distantes de seu domicílio, além de não contribuírem para a superlotação deste tipo de serviço.

Levantamentos mostraram que após três anos de seu início, habitantes de mais de 700 pequenas cidades brasileiras contavam com um médico residente em seu território, não precisando se deslocar para outro município em busca de atendimento médico ou pagar por serviços particulares (MOLINA; TASCA; SUÁREZ, 2016). Até dezembro de 2015, foram recrutados 12.446 médicos, estando em atividade 11.404 profissionais médicos, para atender à demanda do Ministério da Saúde (OPAS, 2015 apud MOLINA; TASCA; SUÁREZ, 2016).

O aperfeiçoamento dos médicos participantes do PMM ocorria mediante oferta de curso de especialização por instituição pública de ensino superior com envolvimento de atividades de ensino, pesquisa e extensão na perspectiva da integração ensinoserviço (BRASIL, 2013a).

Os usuários destacaram ainda o aumento de médicos no Brasil, além da melhoria do atendimento conforme representado nas falas seguintes.

Pra mim é bom, quanto mais médicos pra nós, melhor, porque aqui não temos médico, no Brasil todo, de uma forma geral (E12).

Os médicos que tava [sic] vindo de fora pra melhorar o atendimento (E25).

Diante do exposto, evidenciou-se uma satisfação e uma aceitação dos usuários em relação aos profissionais estrangeiros, sendo outra área com resultados de grande relevância para a avaliação do PMM, inclusive em decorrência das dúvidas levantadas em torno das diferenças existentes na cultura e na linguagem dos profissionais estrangeiros. 
Resultados do relatório do Tribunal de Contas da União (2014) constataram que dentre os 264 pacientes entrevistados, 57\% e 32\% relataram não ter dificuldade e ter tido um pouco de dificuldade, respectivamente, para entender o que o médico intercambista falava.

Um fator que pode ter contribuído para minimizar as diferenças existentes entre os países pode ser atribuído ao fato de que para se candidatar a uma vaga no Programa, os médicos estrangeiros deviam ser especialistas em Medicina Geral Integral, com dez anos de experiência profissional, mínimo de dois anos de trabalho em outro país e conhecimento básico do português. E uma vez no Programa, os médicos realizavam o módulo de acolhimento, que abordava temas sobre o funcionamento do SUS, protocolos da atenção básica e língua portuguesa, com duração de três semanas e carga horária mínima de 120 horas. Ao iniciar suas atividades, os médicos participavam do curso de especialização em saúde familiar e comunitária, com acompanhamento de tutores e supervisores (MOLINA; TASCA; SUÁREZ, 2016).

Verificou-se, a partir da opiniáo dos usuários, mudança no atendimento, permanência e interesse para o trabalho dos médicos do PMM, como se pode observar nos relatos que se seguem.

Mudou o atendimento, porque agora todos os dias tem médico, antes às vezes faltava, entrava um, saía outro, os que vinham não demoravam nada, e ele não, tá permanecendo (E15).

Eu achei interessante porque doutor falou que ele mesmo é desses médicos, que vieram, e assim, os médicos daqui já não tinha mais nem tanta vontade de trabalhar, ele já veio mais interessado do que os que já tavam aqui, a verdade foi essa, os outros que passaram por aqui não tinham tanta vontade assim de trabalhar, nem olhava direito pros pacientes (E27).

Estes achados encontraram apoio na matriz de julgamento (Quadro 1), em que foi constatada a melhoria no atendimento após a implantação do PMM, referida por $74,6 \%$ dos entrevistados.

Resultados de uma pesquisa realizada pela Universidade Federal de Minas Gerais, que ouviu 14.000 pessoas em 700 municípios, mostraram que 94\% dos entrevistados estavam satisfeitos ou muito satisfeitos com o PMM, o que pode ser reflexo da facilidade em estabelecer vínculo com os profissionais ligados ao Programa. Esse resultado coincidiu com os de outras pesquisas e estudos de caso em andamento (ABRASCO, 2016).

Um estudo de campo realizado em municípios pobres das cinco regiôes do Brasil também revelou efeitos positivos do PMM. Nessa pesquisa, observou-se junto a 263 
usuários do SUS alto grau de satisfação nas dimensões tempo de espera para agendar a consulta e atendimento durante a consulta. A maioria relatou que sua privacidade foi respeitada, que os médicos ouviram com atenção suas queixas, deram as informaçôes necessárias, explicaram de forma clara o tratamento e que eles compreenderam as orientações dadas. No caso de médicos intercambistas, a língua espanhola não foi impedimento para a comunicação (SANTOS; COSTAS; GIRARDI, 2015).

Outra pesquisa envolvendo 32 municípios de todas as regióes do Brasil, sendo 14 no Norte, 12 no Nordeste, três no Sudeste, dois no Centro-Oeste e um no Sul, também evidenciou que houve uma satisfação elevada por parte dos usuários, mais especificamente no que concerne ao atendimento médico e à relação médicopaciente, sendo que a grande maioria dos usuários $(98,1 \%)$ considerou que o médico ouviu atentamente todas as suas queixas e $95,8 \%$ dos participantes expressaram que receberam todas as informaçóes necessárias (COMES et al., 2016).

Priorizar a contratação de médicos brasileiros foi outro aspecto levantado por um dos usuários do estudo.

Eu acho que é um absurdo, porque não contrata aqui do Brasil mesmo, e eles trazem de fora, sendo que aqui tem médico capacitado pra atender as pessoas (E11).

O ingresso de profissionais estrangeiros no país se deu principalmente por meio do Projeto de Cooperação da OPAS/OMS (PCMM), implicando grande mobilização de recursos humanos e financeiros submetidos a uma permanente negociação e coordenação entre as partes envolvidas - nação, estados, municípios, organizaçôes da comunidade e de cooperação internacional -, a fim de se alcançar o êxito dessa intervenção sanitária de grande escala, destinada a fortalecer a ESF e o SUS. Assim, a OPAS gerenciou recursos financeiros de um Estado-Membro, Brasil, para mobilizar profissionais da saúde de Cuba (MOLINA; TASCA; SUÁREZ, 2016).

No entanto, havia a alegação de que esses médicos atuavam no país somente com um número de registro autorizado pelo governo, sem a devida aprovação do CFM, já que não era exigido que eles fizessem a prova para revalidação do diploma, o que a Associação Médica Brasileira e o CFM alegavam ser uma medida que retirava dos conselhos a competência para avaliar a qualidade profissional do médico intercambista (SILVA; SANTOS, 2015).

Por outro lado, ressalta-se que a vinda de médicos estrangeiros para o Brasil foi uma medida emergencial adotada pelo governo, tendo em vista o suprimento da demanda 
do mercado, não sendo uma medida para ocupar o lugar dos médicos brasileiros, mas de ocupar as vagas por eles não preenchidas. Apesar disso, a chegada dos estrangeiros gerou um grande desconforto entre a classe médica, sendo que alguns conselhos de medicina se posicionaram contra, alegando que esta medida seria paliativa, ineficaz e abriria margem para atuação de profissionais cuja formação não foi endossada pelos órgãos competentes no Brasil (SCREMIN; JAVORSKI, 2013).

Entretanto, um estudo realizado na Paraíba mostrou que a preocupação da classe médica e de outros organismos nacionais com relação à formação dos médicos estrangeiros não possuía fundamento, pois além de terem uma formação profissional rigorosa, os médicos cubanos passaram por processos seletivos e preparatórios antes de serem enviados aos locais de trabalho (SOUSA; OLIVEIRA SILVA, 2015).

Levando em conta decisóes do Supremo Tribunal Federal (STF) sobre o PMM, bem como estudos que analisaram as dificuldades de provimento de profissionais para regiōes pobres e remotas, vale ser ressaltado, no entanto, a necessidade de considerar o enfrentamento de algumas questôes controversas do PMM, a exemplo dos direitos sociais dos trabalhadores, pois havia uma violação dos direitos trabalhistas ao não reconhecer o vínculo empregatício e assim não garantir direitos como férias, $13^{\circ}$ salário, FGTS, entre outros (SILVA; SANTOS, 2015). O que certamente são fatores que não atraíam os médicos brasileiros a se inserirem no PMM.

No que diz respeito ao aumento de custos para o Brasil, destacou-se esta fala: "Acho que isso tem um custo maior pro Brasil, ainda mais nessa crise que tá agora" (E11). Tal colocação não encontrou subsídios na literatura especializada, ressaltandose que a necessidade de melhorar o acesso aos serviços e cuidado em saúde se torna uma condição indispensável, devendo ser adotadas medidas para melhor distribuir os profissionais e serviços, em especial os médicos no âmbito da atenção básica, já que sua maior concentração ocorre em grandes centros urbanos, com déficits nas regiôes afastadas, marcadas por diferentes vulnerabilidades (COLLAR; NETO; FERLA, 2015).

Assim, diante desta realidade, foi adotada por muitos países a estratégia de atrair profissionais de saúde estrangeiros para atender prioritariamente às áreas consideradas de maior vulnerabilidade, não sendo esta medida exclusiva do Brasil. A exemplo do governo australiano, cujo déficit de médicos em seu território era uma realidade na qual a média para cada 1.000 habitantes nos centros urbanos era 
de 1,8, enquanto nas comunidades rurais e pequenas cidades era de 0,9, em 1991 (VISCOMI; LARKINS; GUPTA, 2013).

A não aprovação do PMM foi referida por uma parcela dos entrevistados, tendo sido apontado, a partir da matriz de avaliação, que muitos usuários não aprovaram o PMM por acharem desnecessário trazer médicos estrangeiros para o país e que o mesmo não foi expresso na prática como prometido pelo governo, alcançando um valor de aprovação de apenas $57 \%$, como pode ser visualizado nas falas que se seguem.

Pelo que ouvi falar parecia que era mil maravilhas, mas na realidade não é nada daquilo, por aqui onde a gente mora náo foi aquela coisa toda [...] o médico, aquele carinho com o paciente, o atendimento sendo rápido, e aqui nada disso aconteceu, não sei nos outros postos (E16).

É complicado, eu achei muito ruim, eu não gostei dessa ideia não (E19).

A falta de aprovação do PMM pelos usuários poderia estar relacionada a fatores que iam para além do Programa, próprios da organização da APS e da rede de serviços de saúde local, que dificultavam a acessibilidade ao serviço, conforme exposto na matriz (quadro 1) e relatado anteriormente. Comes et al. (2016) enfatizaram sugestóes para melhoria da responsividade do PMM, como adequação $\mathrm{da}$ infraestrutura, maior disponibilidade de medicamentos, mais profissionais inseridos no mesmo, mais especialistas, mais apoio de transporte para acesso às comunidades rurais e remotas, que deveriam ser levadas em consideração pelos gestores federais e municipais do SUS, de modo a contribuir para a garantia do acesso e do direito constitucional à saúde.

A insatisfação poderia estar relacionada também com o tempo de espera, relativo ao agendamento de consulta especializada e realização de consulta na unidade, o que evidenciava dificuldades ligadas à organização do serviço de saúde e à garantia de acesso a atençáo especializada em tempo oportuno e resolutivo. Esse tipo de insatisfação referia-se a um dos principais entraves da atenção básica, que deve ser a porta de entrada para uma rede de serviços resolutivos de acesso universal (SANTIAGO et al., 2013).

No entanto, mesmo diante destes contrapontos ora apresentados, observou-se que houve uma aprovação do PMM pela maior parte da comunidade assistida, o que também foi verificado em várias pesquisas, como, por exemplo, a realizada pelo Datafolha em agosto de 2013, que mostrou que 54\% da população entrevistada o aprovou, sendo que a regiāo Nordeste concentrou o maior percentual de aprovação 
(MORAIS et al., 2014). Em outra pesquisa, realizada por Pereira, Silva e Santos (2015), em comunidades quilombolas, constatou-se que o PMM colaborou não só para uma melhor viabilização das ações de APS nos territórios, como também demonstrou que é viável a fixação de médicos nas equipes de saúde, mesmo em áreas mais distantes e vulneráveis. Desmistificando, assim, o modelo largamente adotado voltado somente ao atendimento individual e de uma equipe de saúde que conta com a presença esporádica e rotativa do profissional médico.

As falas dos usuários destacaram ainda o atendimento do profissional médico, que também é avaliado na matriz de julgamento, sendo classificado como resolutivo por boa parcela dos usuários (71,3\%). Por sua vez, Thiede, Akweongo e Mcintyre (2014) colocaram que a aceitabilidade está relacionada aos fatores subjetivos, culturais e sociais, que direcionam a avaliação dos indivíduos sobre os serviços de saúde, que sofrem influência de fatores como idade, sexo, etnia, linguagem, crenças, cultura e condição socioeconômica. A aceitabilidade diz respeito às expectativas dos usuários sobre a organização do serviço, aceitação quanto ao cuidado prestado, ao respeito no atendimento, na escuta às suas queixas, com sua compreensão das explicações médicas sobre seu estado de saúde e na possibilidade de discussão das alternativas de cuidado.

Desse modo, as falas dos usuários revelaram opiniōes diversas acerca do atendimento recebido pelo médico. Alguns relatos muito positivos de melhorias na maneira em que foram acolhidos e orientados foram destacados pelos usuários do estudo.

Ele é educado, muito legal, antes tinha médico que a gente tinha medo até de conversar (E13).

Chega no horário, conversa, tem aquela coisa de conversar, o outro não, às vezes nem conversava, perguntava o que tinha, passava receita e pronto. Esse tem o cuidado de chegar no horário, conversar, atender a gente (E16).

$\mathrm{O}$ atendimento dele é bem melhor do que o médico de antes, as consultas da gente são mais esclarecidas. Ele é muito atencioso, as consultas são demoradas, tem mais paciência de conversar com a gente (E27).

As falas mostraram que a comunidade assistida percebeu uma mudança significativa no atendimento recebido. A satisfação com o trabalho dos profissionais é um importante resultado para a ESF, que tem no trabalho dos profissionais e na sua relação com a população o elemento primordial de sua legitimação na 
organização do sistema de saúde, resultado semelhante aos encontrados por Santiago et al. (2013), que evidenciaram o trabalho dos profissionais como um componente bem avaliado pelos usuários.

Sobre a facilidade na comunicação, algumas falas mostraram que também houve uma boa mudança nesse sentido.

Essa é melhor que a outra que tava [sic], porque a outra a gente não entendia direito, não entendia a forma dela falar, que ela era de fora, e essa agora não, a gente entende tudo (E6).

Enfatiza-se que a comunicação em saúde não é somente uma estratégia para prover indivíduos e coletividade de informaçôes, mas uma ferramenta fundamental para desenvolver ações de educação em saúde por compartilhar conhecimentos e práticas que podem contribuir para melhorar a condição de vida, representando um aspecto fundamental para o acolhimento. Tal fato corrobora o encontrado em estudo realizado por Bezerra et al. (2014), ao mostrarem os benefícios do processo de comunicação na assistência à saúde para os profissionais e para os usuários, em razão de promover uma interação e, consequentemente, uma maior participação da clientela assistida nas açôes e, dessa forma, no alcance de metas estabelecidas.

Alguns entrevistados, porém, referiram que não conseguiram compreender bem a fala daqueles médicos que eram de outro país, fazendo referência ao profissional que tinha anteriormente na unidade de saúde.

Mas na minha opiniáo é que eu tenho dificuldade de falar com esse povo, às vezes eu até demoro de vir aqui por esse motivo, que às vezes fala e a gente fica o tempo todo ali pra entender (E19).

Só que ela tem uma dificuldade maior pra falar, porque ela é cubana, a outra eu entendia mais (E29).

No entanto, percebeu-se que a comunicação em si não foi um problema relevante encontrado na presente pesquisa, pois foi um fator referido por apenas dois dos entrevistados. Pesquisa realizada pela Universidade Federal de Minas Gerais identificou algo semelhante ao aqui referido, que quando indagados sobre dificuldades de comunicação, a maioria dos entrevistados (87\%) responderam que não tiveram nenhuma dificuldade e somente para uma pequena parte (3\%), ela foi importante. Esses números comparados na mesma pesquisa com médicos brasileiros não participantes do PMM, grupo utilizado como controle, resultaram em $95 \% \mathrm{e}$ 2\%, respectivamente (PINTO et al., 2017). 
Na literatura, encontrou-se bem definida a relação entre comunicação médicopaciente e qualidade de atenção, sendo que uma boa comunicação determina uma atenção médica mais humanizada e aporta maior qualidade ao serviço e os aspectos comunicacionais são importantes na aderência aos tratamentos (BIANCA BARLLETA; DE SOUZA GENNARI; CIPOLOTTI, 2012). Assim, fica claro que entre os entrevistados os médicos foram bem aceitos, trazendo mudanças práticas com melhoria no atendimento, sendo sentida pela maioria da população aqui representada.

Diante do exposto, ficou evidente que a matriz apresentada corroborou o encontrado nas falas, endossando que o Programa possui um bom grau de implantação no município, possuindo, no entanto, alguns entraves que precisam ser vencidos para que se consolide como uma política pública. Destaca-se a ampliação do acesso ao atendimento médico em áreas desprovidas desse serviço, com atendimento das necessidades de saúde dos usuários, apesar de questôes estruturais e de organização dos trabalhos que impulsionam a insatisfação, mas suscitam a necessidade de mudanças em nível de gestão e do processo de trabalho da eSF. E como limitaçóes do estudo, enfatiza-se sua realização no contexto locorregional, que apresenta dificuldade de inserção de médicos brasileiros, o que requer ampliar esta avaliação para outras realidades.

\section{Considerações finais}

Esta pesquisa permitiu observar que, apesar do desconhecimento acerca do PMM por parte da clientela assistida, houve uma forte aprovação popular em torno do mesmo, pois a melhoria da assistência foi sentida no cotidiano dos serviços de saúde. Assim, ficou claro que para a população o que importava era a resolutividade de seus problemas de saúde, que a porta de entrada a recebesse e a acolhesse, sendo a partir daí estabelecido vínculo, de modo a tornar a atenção básica sua referência para os demais níveis da atenção.

No entanto, ressalta-se que era preciso uma melhor divulgação em torno do assunto, haja vista que se tratava de uma política pública que merecia ser conhecida e discutida pela população, pois somente apropriando a mesma acerca de um determinado tema é que a torna apta para acompanhar, avaliar e fiscalizar se os objetivos propostos foram cumpridos. Desse modo, o conhecimento é fundamental para o exercício do controle social, sendo este um direito e um dever de todo cidadão. 
Outra questão verificada foi que existiam algumas discordâncias em torno do PMM, a exemplo da abertura do mercado brasileiro para os médicos estrangeiros, sendo colocado que este espaço deveria ser ocupado por médicos brasileiros, o que requeria uma série de adequaçôes em sua base jurídica-operacional, a fim de possibilitar o estabelecimento das garantias trabalhistas, para então atrair e fixar os mesmos.

Fator também encontrado foi que, apesar da ampla aprovação, esta não foi unânime, sendo colocada algumas vezes a ausência de mudanças após a implantação do PMM, muitas das quais relacionadas às debilidades encontradas na organização e acesso dos serviços da atenção básica, mostrando a necessidade de maiores investimentos na área no intuito de permitir que a mesma realizasse seu papel de resolver $80 \%$ da demanda dos problemas de saúde da população, como preconizado pela Política Nacional da Atenção Básica.

Desse modo, o presente estudo tratou de um tema extremamente relevante ao abordar uma política de saúde criada para enfrentar a carência de profissionais médicos na APS, que se caracteriza como um grave problema na saúde pública, visto que fragiliza a mesma como porta de entrada preferencial ao sistema de saúde. Assim sendo, a pesquisa alcançou o objetivo proposto, pois investigou a opinião da comunidade acerca do assunto em questão, avaliando a implantaçáo do PMM no município, que alcançou uma classificação satisfatória. ${ }^{1}$

\section{Referências}

ASSOCIAÇÃO BRASILEIRA DE SAÚDE COLETIVA (ABRASCO). Avaliação de Política Pública: o Programa Mais Médicos. Plataforma de conhecimentos Programa Mais Médicos. Disponível em: <http://pesquisa.bvsalud.org/pmm/resource/pt/pesq pmm-95\#>. Acesso em: 20 maio 2016.

ALVES, C. K. A. et al. Interpretação e Análise das informaçôes: o uso de matrizes, critérios, indicadores e padrôes. In: SAMICO, I. et al. (Org.). Avaliação em saúde: bases conceituais e operacionais. Rio de Janeiro: Medbook, 2010.

BARDIN, L. Análise de conteúdo. SP: Edições 70, 2011.

BIANCA BARLETTA, J.; DE SOUZA GENNARI, M.; CIPOLOTTI, R. A perspectiva cognitivo-comportamental dos aspectos psicossociais que interferem na qualidade da relação médico-paciente. Psicologia em Revista. Belo Horizonte, v. 17, n. 3, p. 396-413, 2012. 
BEZERRA, I. M. P. et al. Comunicação no Processo Educativo Desenvolvido pelos Enfermeiros: As Tecnologias de Saúde em Análise. Saúde \& Transformação Social. Florianópolis, v. 5, n. 3, p. 42-48, 2014.

BRASIL. Lei n. ${ }^{\circ}$ 12.871, de 22 de outubro de 2013. Institui o Programa Mais Médicos, altera as Leis no 8.745, de 9 de dezembro de 1993, e no 6.932, de 7 de julho de 1981, e dá outras providências. Brasília, DF: Diário Oficial [da República Federativa do Brasil], 23 out. 2013a.

. Ministério da Saúde. Portaria Interministerial GM/MS/MEC no 1.369, de 8 de julho de 2013. Dispóe sobre a implementação do Projeto Mais Médicos para o Brasil. Brasília, DF: Diário Oficial da União, 9 jul. 2013 b.

Informe Mais Médicos. Ministério da Saúde. [citado 2014 abr. 10] 2014. Disponível em: <http://portalsaude.saude.gov.br/images/pdf/2013/setembro/27/2013-08-21-informe-maismedicos.pdf>. Acesso em: 7 jun. 2017.

CARRYL, J.; ROSSATO, L.; PRADOS, R. M. N. Programa Mais Médicos. Revista Diálogos Interdisciplinares. Mato Grosso do Sul, v. 5, n. 2, p. 1-8, 2016.

CERQUEIRA, J. P.; ALVES, S. M. C. A Constitucionalidade do Projeto Mais Médicos para o Brasil. Cadernos Ibero-Americanos de Direito Sanitário. Brasília, v. 5, n. 2, p. 91-107, 2016.

COLLAR, J. M.; NETO, J. B. A.; FERLA, A. A. Formulação e impacto do Programa Mais Médicos na atenção e cuidado em saúde: contribuições iniciais e análise comparativa. Saúde em Redes. Porto Alegre, v. 1, n. 2, p. 43-56, 2015.

COMES, Y. et al. Avaliação da satisfação dos usuários e da responsividade dos serviços em municípios inscritos no Programa Mais Médicos. Ciência \& Saúde Coletiva. Rio de Janeiro, v. 21, n. 9, p. 2749-2759, 2016.

CRUZ, M. M. Avaliação de Políticas e Programas de Saúde: Contribuições para o Debate. In: MATTOS, R. A.; BAPTISTA, T. W. F. (Org.). Caminhos para análise das politicas de saúde. Porto Alegre: Rede UNIDA, 2015.

DI JORGE, F. M. Estudo jurídico do programa mais médicos. Acta JUS. Paraná, v. 1, n. 1, p. 24-34, 2013.

FIGUEIRÓ, A. C., CAZARIN, G. Justificando as conclusóes. Texto de apoio ao Módulo 5. In: SAMICO, I. et al. (Org.). Avaliaçâo em saúde: bases conceituais e operacionais. Rio de Janeiro: Medbook, 2010.

LEAL, R. G. Patologias corruptivas nas relaçôes entre Estado, administração pública e sociedade: causas consequências e tratamentos. Santa Cruz do Sul: Ed. Unisc, 2013.

MOLINA, J.; TASCA, R.; SUÁREZ, J. Monitoramento e avaliação do Projeto de Cooperação da OPAS/OMS com o Programa Mais Médicos: reflexóes a meio caminho. Ciência \& Saúde Coletiva. Rio de Janeiro, v. 21, n. 9, p. 2925-2933, 2016. 
MORAIS, I. et al. Jornais Folha de São Paulo e Correio Braziliense: o que dizem sobre o programa mais médicos? Revista da Escola de Enfermagem da USP. São Paulo, v. 48, n. 2, p. 112-120, 2014.

PADILHA, A. R. S.; OLIVA, A. M.; BELCHIOR, M. A. Exposição de Motivos Interministerial n. ${ }^{\circ}$ 24-2013/MS-MEC-MP vinculada à Lei Federal n.o 12.871/2013. Brasília, 2013. 8 p. (Exposição de Motivos Interministerial).

PEREIRA, L. L.; SILVA, H. P.; SANTOS, L. M. P. Projeto mais médicos para o Brasil: estudo de caso em comunidades quilombolas. Revista da ABPN. Goiânia, v. 7, n. 16, p. 28-51, 2015.

PINTO, H. A. et al. Programa Mais Médicos: avaliando a implantação do Eixo Provimento de 2013 a 2015. Interface (Botucatu). Botucatu, v. 21, supl. 1, p. 1087-1101, 2017.

SANTIAGO, R. F. et al. Qualidade do atendimento nas Unidades de Saúde da Família no município de Recife: a percepção dos usuários. Ciência \& Saúde Coletiva. Rio de Janeiro, v. 18, n. 1, p. 35-44, 2013.

SANTOS, L. M. P.; COSTAS, A. M.; GIRARDI, S. N. Programa Mais Médicos: uma ação efetiva para reduzir iniquidades em saúde. Ciência \& Saúde Coletiva. Rio de Janeiro, v. 20, n. 11, p. 3547-3552, 2015.

SCHIAVO, R. Health Communication: from theory to practice, San Francisco: Jossey-Bass, 2007. SCREMIN, L.; JAVORSKI, E. O enquadramento das notícias sobre os estrangeiros do programa mais médicos. In: 9 CICLO DE DEBATES SOBRE JORNALISMO. Anais... UniBrasil, 2013 SILVA, S. M.; SANTOS, L. M. P. Estudo das Açóes Diretas de Inconstitucionalidade do Programa Mais Médicos. Cadernos Ibero-Americanos de Direito Sanitário. Brasília, v. 4, n. 1, p. 68-82, 2015. SILVA, T. R. B. et al . Percepção de usuários sobre o Programa Mais Médicos no município de Mossoró, Brasil. Ciência \& Saúde Coletiva. Rio de Janeiro, v. 21, n. 9, p. 2861-2869, 2016.

SOUSA, D.; OLIVEIRA SILVA, R. J. O Programa Mais Médico na Perspectiva dos Atores Sociais Responsáveis por sua Implantação e dos Beneficiários no Município de Boqueirão, PB. REUNIR: Revista de Administração, Contabilidade e Sustentabilidade. Campina Grande, v. 5, n. 3, p. 59-75, 2015.

TRIBUNAL DE CONTAS DA UNIÃO (TCU). Auditoria operacional: Programa Mais Médicos e Projeto Mais Médicos para o Brasil; avaliação da eficácia do programa. TC no 005.391/2014-8.

THIEDE, M.; AKWEONGO, P.; McINTYRE, D. Explorando as dimensóes do acesso. In: MCINTYRE, D.; MOONEY, G. Aspectos econômicos da equidade em saúde. Rio de Janeiro: Fiocruz, 2014, p. 137-162.

VISCOMI, M.; LARKINS, S.; GUPTA, T. Recrutment and retention of general practitioners in rural Canada and Australia: a review of the literature. Canadian Journal of Rural Medicine, v. 18, n. 1, p. 13-23, 2013. 
| Página 22 de 23

\section{Nota}

${ }^{1}$ P. M. M. Padre realizou a concepção, obtenção dos dados e redação do manuscrito. I. E. Martins Filho foi responsável pelo desenho da pesquisa e revisão crítica do manuscrito. V. P. Rodrigues realizou a análise e interpretação dos dados. 


\section{Abstract}

\section{The Mais Médicos Program in the user's} perspective: an evaluating research

The Mais Médicos Program (MMP) appeared in 2013 as a measure to face the absence of doctors in primary care. It generated controversy in the society before the opening of the Brazilian market for foreign professionals, with disapproval by the medical category, but with apparent popular acceptance. Thus, this study aimed to evaluate the implementation of PMM of a countryside municipality in Bahia state, Brazil, through the users. This is an evaluative research performed in 11 family health teams in Bahia countryside, that had doctors bound by Program, with the participation of 30 users. A semi-structured interview was conducted and the data were analyzed according to the thematic content analysis technique. A judgment matrix was also constructed in order to point out the merit achieved by the MMP. The results revealed that the implementation of the Program was satisfactory, with a strong popular approval around, even if there was a superficial knowledge about it, or even a total lack of knowledge. It was also evidenced that it would not be necessary for foreign doctors to come to the country, once the necessary legal adjustments were made in order of the Program to attract and fix the Brazilian professionals.

Keywords: right to health; public policies; primary health care. 